\title{
Wavelet for Predicting Soil Nutrients using Remotely Sensed Satellite Images
}

\author{
Viraj A. Gulhane \\ Assistant Professor, \\ Dept of Electronics \& Telecom., \\ Sipna COET, Amravati
}

\author{
Sandeep V. Rode \\ Professor, \\ Dept of Electronics \& Telecom., \\ Sipna COET Amravati
}

\author{
Chaitanya B. Pande \\ Senior Research Fellow, \\ AICRP for Dry Land, \\ Dr. PDKV, Akola
}

\begin{abstract}
In country like India, where agricultural economy plays major role, understanding and tracking the soil nutrients are essential. However, the chemical analysis, which determines the nutrient contents of soil, is expensive and time consuming. Hence, we attempt to exploit remote sensing imagery for estimating them. This paper analyzes the correlation between the level of soil nutrients and wavelet decompositions of remote sensing imagery of a particular region. Four renowned wavelet transformations such as Daubechies, Symlet, Biorthogonal and Coiflet are used to represent the image in wavelet domain. Subsequently, here exploit a neural network model to predict the soil nutrient content using the principle wavelet components. Experimental analysis on the prediction accuracy and the correlation measure reveals the suitability of each wavelet transformation of remote sensing imagery in predicting the soil nutrients.
\end{abstract}

\section{General Terms}

Remote Sensing, Image Processing, Analysis.

\section{Keywords}

Soil nutrient; prediction; wavelet.

\section{INTRODUCTION}

Remote sensing is a prominent technology to acquire spatially distributed parameters to define both temporal and spatial properties of land surface [2] [10]. This makes ease of predicting soil nutrients, especially in agriculture based countries like India [3]. Since these methods are nondestructive and computationally efficient, they gain wide attention recently [7]. These methods acquire hyperspectral data $[1,11,12,18]$ to model the characteristics of soil nutrients, often termed as soil nutrient prediction models [16].

Generally, a soil nutrient prediction model falls in any of the three categories such as linear models, nonlinear models and integrated models [20]. Principle component regression, partial least square regression and multi-linear regression are few examples for linear models $[17,19,22]$, whereas artificial neural network, locally weighted regression are examples for nonlinear models $[4,20]$. Integrated or hybrid models results from the combination of two or more linear or nonlinear models or combination of both [21].

The hyperspectral data was reported to be useful, yet the complexities reside on image acquisition and processing steps have led the way for finding alternatives [8-10]. Moreover, the hyperspectral data is not consistent to define spatial variance based on soil nutrients [5, 13, 15]. Despite hyperspectral data have been used in [14], the wavelet decompositions have played crucial role to predict the biomass from temperature deciduous forest. Being motivated by this work, we attempt to study the ability of wavelet decomposed remote sensing imagery on predicting soil nutrient contents. We describe the study region and preliminary materials for the study in Section II. Section III presents the correlation analysis and the outcome, whereas Section IV presents the prediction analysis and the practical implications. Section V concludes the paper.

\section{STUDY AREA AND MATERIALS}

By considering four major cultivating regions of Maharashtra province - India, namely, Baggi, Ibrahimpur, Mogara and Wai, as study region from which soil samples are acquired various regions and the chemical analysis is conducted. From the chemical analysis, results determine the level of significant nutrients such as $\mathrm{pH}$, electrical conductivity, carbon, phosphorous and potassium.

Meantime, by acquiring the satellite imagery of the study regions from "Google Earth". Five image samples are acquired for every region at two different altitudes, say $500 \mathrm{~m}$ and $1 \mathrm{~km}$. Hence, here obtain 10 images/ study region, which are preprocessed to remove watermarks and annotations followed by resizing them uniformly.

\section{CORRELATION ANALYSIS}

\subsection{Methodology}

The architectural view of the correlation analysis is presented in Figure 1. Our preliminary work presents more details about the correlation analysis [23]. Let $\{I\}_{N_{R} \times N_{S}}:\{I\} \supset\left\{I_{0.5}\right\},\left\{I_{1}\right\}$ be the set of acquired images, where $N_{R}, N_{S},\left\{I_{0.5}\right\}$ and $\left\{I_{1}\right\}$ are the number of study regions, number of samples/study region, image set acquired at $0.5 \mathrm{~km}$ altitude and image set acquired at $1 \mathrm{~km}$, respectively.

The images are subjected to wavelet decomposition from its own $\mathfrak{R}^{M \times N}$ domain. The wavelet decompositions are accomplished using renowned wavelets such as Daubechies wavelet, Symlet wavelet, Biorthogonal wavelet and Coiflet wavelet. The transformation leads to four decomposed set constituents for $i_{r s}$, which can be referred as $\left\{A_{k}, H_{k}, V_{k}, D_{k}\right\}=W_{k}\left(i_{r s}\right)$, where, $A_{k}, H_{k}, V_{k}$ and $D_{k}$ are the low frequency components, horizontal and vertical high frequency components and diagonal components, of $k^{\text {th }}$ wavelet respectively, $k=1,2,3$ and 4 refers to Daubechies wavelet, Symlet wavelet, Biorthogonal wavelet and Coiflet wavelet, respectively. We consider low frequency components in this paper for the further analysis.

$3 \mathrm{D}$ representation can be given for the extracted wavelet samples as $\{A\}_{4 \times N_{R} \times N_{S}}$. Here, $\{A\}$ is the wavelet decompositions of two different spatial representations, $\left\{I_{0.5}\right\}$ and $\left\{I_{1}\right\}$ and hence we fuse both the decompositions 
to formulate them as single representation using simple averaging method. The fused set of wavelet decompositions can be represented as $\left\{A^{F}\right\}:\left|A^{F}\right|=4 \times N_{R} \times N_{S} / 2$.

A dimensional conversion process is applied over $\left\{A^{F}\right\}$ to obtain 1D array of decomposed set, termed as $\left\{A^{1 D}\right\}$, using column-wise operation. Further, we reduce the dimensionality of $\left\{A^{1 D}\right\}$ using principle component analysis (PCA) followed by calculating the correlation coefficient for the wavelet parameter and the output variable, i.e., soil nutrient intensity.

\subsection{Findings}

We have considered five principle components of wavelet descriptors to understand its correlation with soil nutrient contents. The correlation coefficients of the principle components of each wavelet descriptor on describing each soil nutrient is tabulated in Table I.

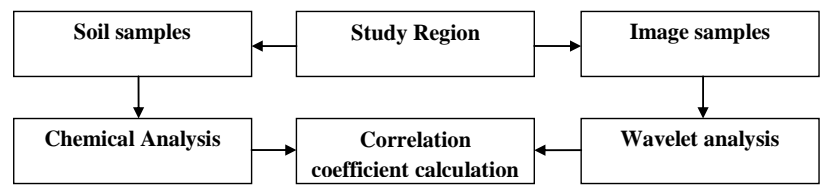

Fig 1: Architectural view of correlation analysis

Table 1: Correlation between the principle components of each wavelet and the soil nutrients.

\begin{tabular}{|c|c|c|c|c|c|}
\hline $\begin{array}{c}\text { Soil } \\
\text { Nutrients }\end{array}$ & $\begin{array}{c}\text { Principle } \\
\text { component } \\
\mathrm{s}\end{array}$ & $\begin{array}{l}\text { Daubechie } \\
\text { s wavelet }\end{array}$ & $\begin{array}{l}\text { Symlet } \\
\text { wavelet }\end{array}$ & $\begin{array}{c}\text { Biorthogona } \\
\text { I wavelet }\end{array}$ & $\begin{array}{c}\text { Coiflet } \\
\text { wavelet }\end{array}$ \\
\hline \multirow{5}{*}{$\mathrm{pH}$} & 1 & $0.1742 \mathrm{e}-16$ & $\begin{array}{c}0.1161 \mathrm{e} \\
-16\end{array}$ & $0.1742 \mathrm{e}-16$ & $\begin{array}{c}- \\
0.0581 \mathrm{e} \\
-16\end{array}$ \\
\hline & 2 & 0 & 0 & 0 & $\begin{array}{c}0.1595 \\
\mathrm{e}-16\end{array}$ \\
\hline & 3 & 0 & 0 & 0 & $\begin{array}{c}- \\
0.0493 \mathrm{e} \\
-16\end{array}$ \\
\hline & 4 & $0.0467 \mathrm{e}-16$ & $\begin{array}{c}0.0410 \mathrm{e} \\
-16\end{array}$ & $0.0467 \mathrm{e}-16$ & $\begin{array}{c}- \\
0.1709 \mathrm{e} \\
-16\end{array}$ \\
\hline & 5 & $\begin{array}{c}-0.0273 e- \\
16\end{array}$ & 0 & $-0.0273 \mathrm{e}-16$ & $\begin{array}{c}- \\
0.0467 \mathrm{e} \\
-16\end{array}$ \\
\hline \multirow{5}{*}{$\begin{array}{c}\text { Electrical } \\
\text { Conductivit } \\
\text { y }\end{array}$} & 1 & $0.0278 \mathrm{e}-16$ & 0 & $0.0278 \mathrm{e}-16$ & $\begin{array}{c}0.0278 \mathrm{e} \\
-16\end{array}$ \\
\hline & 2 & $\begin{array}{c}-0.0509 \mathrm{e}- \\
16\end{array}$ & 0 & $-0.0509 \mathrm{e}-16$ & $\begin{array}{c}- \\
0.1019 \mathrm{e} \\
-16\end{array}$ \\
\hline & 3 & $\begin{array}{c}-0.0945 e- \\
16\end{array}$ & $\begin{array}{c}- \\
0.0236 \mathrm{e} \\
-16\end{array}$ & $-0.0945 \mathrm{e}-16$ & $\begin{array}{c}- \\
0.0236 \mathrm{e} \\
-16\end{array}$ \\
\hline & 4 & $\begin{array}{c}-0.1789 \mathrm{e}- \\
16\end{array}$ & $\begin{array}{c}0.2619 e \\
-16\end{array}$ & $-0.1789 \mathrm{e}-16$ & $\begin{array}{c}0.0524 \mathrm{e} \\
-16\end{array}$ \\
\hline & 5 & $\begin{array}{c}-0.0524 \mathrm{e}- \\
16\end{array}$ & $\begin{array}{c}0.2237 \mathrm{e} \\
-16\end{array}$ & $-0.0524 \mathrm{e}-16$ & $\begin{array}{c}- \\
0.2237 \mathrm{e} \\
-16\end{array}$ \\
\hline \multirow{3}{*}{ Carbon } & 1 & $0.1516 \mathrm{e}-16$ & $\begin{array}{c}0.0505 \mathrm{e} \\
-16\end{array}$ & 0.1516 e- 16 & 0 \\
\hline & 2 & $0.3703 \mathrm{e}-16$ & $\begin{array}{c}0.2778 \mathrm{e} \\
-16\end{array}$ & $0.3703 \mathrm{e}-16$ & 0 \\
\hline & 3 & 0 & - & 0 & 0 \\
\hline
\end{tabular}

\begin{tabular}{|c|c|c|c|c|c|}
\hline & & & $\begin{array}{c}0.1288 \mathrm{e} \\
-16\end{array}$ & & \\
\hline & 4 & $0.0813 \mathrm{e}-16$ & $\begin{array}{c}0.1190 \mathrm{e} \\
-16\end{array}$ & $0.0813 \mathrm{e}-16$ & $\begin{array}{c}- \\
0.2975 \mathrm{e} \\
-17\end{array}$ \\
\hline & 5 & $0.0416 \mathrm{e}-16$ & $\begin{array}{c}- \\
0.0813 \mathrm{e} \\
-16\end{array}$ & $0.0416 \mathrm{e}-16$ & $\begin{array}{c}0.8129 \\
\text { e-17 }\end{array}$ \\
\hline \multirow{5}{*}{ Phosphorous } & 1 & $0.6332 \mathrm{e}-16$ & $\begin{array}{c}- \\
0.6385 \mathrm{e} \\
-16\end{array}$ & $0.6332 \mathrm{e}-16$ & $\begin{array}{c}0.4696 \\
\mathrm{e}-16\end{array}$ \\
\hline & 2 & $0.3722 \mathrm{e}-16$ & $\begin{array}{c}- \\
0.1837 \mathrm{e} \\
-16\end{array}$ & $0.3722 \mathrm{e}-16$ & $\begin{array}{c}-0.2030 \\
\mathrm{e}-16\end{array}$ \\
\hline & 3 & $\begin{array}{c}-0.0022 \mathrm{e}- \\
16\end{array}$ & $\begin{array}{c}- \\
0.1143 \mathrm{e} \\
-16\end{array}$ & $-0.0022 \mathrm{e}-16$ & $\begin{array}{c}0.0336 \\
\mathrm{e}-16\end{array}$ \\
\hline & 4 & $0.0424 \mathrm{e}-16$ & $\begin{array}{c}- \\
0.2585 \mathrm{e} \\
-16\end{array}$ & $0.0424 \mathrm{e}-16$ & $\begin{array}{c}-0.1789 \\
\text { e-16 }\end{array}$ \\
\hline & 5 & $0.0497 \mathrm{e}-16$ & $\begin{array}{c}0.2377 \mathrm{e} \\
-16\end{array}$ & $0.0497 \mathrm{e}-16$ & $\begin{array}{c}0.3396 \\
\mathrm{e}-16\end{array}$ \\
\hline \multirow{5}{*}{ Potassium } & 1 & $0.0792 \mathrm{e}-16$ & 0 & $0.0792 \mathrm{e}-16$ & 0 \\
\hline & 2 & $0.0484 \mathrm{e}-16$ & $\begin{array}{c}-0.2903 \\
\mathrm{e}-16\end{array}$ & $0.0484 \mathrm{e}-16$ & $\begin{array}{c}-0.1935 \\
\mathrm{e}-16\end{array}$ \\
\hline & 3 & 0.0897 e-16 & $\begin{array}{c}0.0897 \\
\text { e-16 }\end{array}$ & 0.0897 e-16 & $\begin{array}{c}0.0449 \\
\mathrm{e}-16\end{array}$ \\
\hline & 4 & $\begin{array}{c}-0.2549 \mathrm{e}- \\
16\end{array}$ & $\begin{array}{c}-0.1741 \\
\mathrm{e}-16\end{array}$ & -0.2549 e-16 & $\begin{array}{c}-0.0995 \\
\mathrm{e}-16\end{array}$ \\
\hline & 5 & $\begin{array}{c}-0.0497 \mathrm{e}- \\
16\end{array}$ & 0 & -0.0497 e-16 & $\begin{array}{c}-0.0850 \\
\mathrm{e}-16\end{array}$ \\
\hline
\end{tabular}

Table 2: Performance of wavelates on predicting the soil nutrients

\begin{tabular}{|c|c|c|c|c|c|c|c|c|c|c|}
\hline \multirow{2}{*}{$\begin{array}{c}\text { Soil } \\
\text { nutri } \\
\text { ents }\end{array}$} & \multicolumn{2}{|c|}{$\begin{array}{c}\text { pH } \\
(\text { Actual }= \\
7.94)\end{array}$} & \multicolumn{2}{|c|}{$\begin{array}{c}\text { Electrical } \\
\text { Conductivi } \\
\text { ty (Actual } \\
=0.37 \text { ) }\end{array}$} & \multicolumn{2}{|c|}{$\begin{array}{c}\text { Carbon } \\
\text { (Actual = } \\
\mathbf{0 . 0 3})\end{array}$} & \multicolumn{2}{|c|}{$\begin{array}{l}\text { Phosphoro } \\
\text { us (Actual } \\
=\mathbf{2 3} \text { ) }\end{array}$} & \multicolumn{2}{|c|}{$\begin{array}{c}\text { Potassium } \\
\text { (Actual = } \\
\text { 792) }\end{array}$} \\
\hline & $\begin{array}{l}\text { Pre } \\
\text { dict } \\
\text { ed }\end{array}$ & $\begin{array}{c}E r \\
r o \\
r\end{array}$ & $\begin{array}{l}\text { Pre } \\
\text { dict } \\
\text { ed }\end{array}$ & $\begin{array}{c}\text { Err } \\
\text { or }\end{array}$ & $\begin{array}{l}\text { Pre } \\
\text { dict } \\
\text { ed }\end{array}$ & $\begin{array}{c}\text { Err } \\
\text { or }\end{array}$ & $\begin{array}{l}\text { Pre } \\
\text { dict } \\
\text { ed }\end{array}$ & $\begin{array}{c}\text { Err } \\
\text { or }\end{array}$ & $\begin{array}{l}\text { Pre } \\
\text { dict } \\
\text { ed }\end{array}$ & $\begin{array}{c}\text { Err } \\
\text { or }\end{array}$ \\
\hline $\begin{array}{c}\text { Daub } \\
\text { echie } \\
\mathrm{s} \\
\text { wavel } \\
\text { et }\end{array}$ & $\begin{array}{c}8.21 \\
3\end{array}$ & $\begin{array}{c}0 . \\
27 \\
3\end{array}$ & $\begin{array}{c}0.59 \\
739\end{array}$ & $\begin{array}{l}0.2 \\
27 \\
39\end{array}$ & $\begin{array}{l}0.12 \\
313\end{array}$ & $\begin{array}{l}0.0 \\
93 \\
13\end{array}$ & $\begin{array}{c}41.0 \\
431\end{array}$ & $\begin{array}{l}18 . \\
04 \\
31\end{array}$ & $\begin{array}{c}128 \\
0.89 \\
13\end{array}$ & $\begin{array}{l}488 \\
.89 \\
13\end{array}$ \\
\hline $\begin{array}{c}\text { Syml } \\
\text { et } \\
\text { wavel } \\
\text { et }\end{array}$ & $\begin{array}{c}8.41 \\
73\end{array}$ & $\begin{array}{l}0 . \\
47 \\
73\end{array}$ & $\begin{array}{l}0.31 \\
661\end{array}$ & $\begin{array}{l}0.0 \\
53 \\
39\end{array}$ & $\begin{array}{l}0.47 \\
067\end{array}$ & $\begin{array}{l}0.4 \\
40 \\
67\end{array}$ & $\begin{array}{l}47.0 \\
524\end{array}$ & $\begin{array}{c}24 . \\
05 \\
24\end{array}$ & $\begin{array}{c}106 \\
8.74 \\
08\end{array}$ & $\begin{array}{l}276 \\
.74 \\
08\end{array}$ \\
\hline $\begin{array}{c}\text { Biort } \\
\text { hogo } \\
\text { nal } \\
\text { wavel } \\
\text { et }\end{array}$ & $\begin{array}{c}7.96 \\
94\end{array}$ & $\begin{array}{l}0 . \\
02 \\
94\end{array}$ & $\begin{array}{l}0.36 \\
249\end{array}$ & $\begin{array}{l}0.0 \\
07 \\
51\end{array}$ & $\begin{array}{l}0.21 \\
532\end{array}$ & $\begin{array}{l}0.1 \\
85 \\
32\end{array}$ & $\begin{array}{c}- \\
10.1 \\
245\end{array}$ & $\begin{array}{r}33 . \\
12 \\
45\end{array}$ & $\begin{array}{c}402 . \\
375 \\
5\end{array}$ & $\begin{array}{l}389 \\
.62 \\
45\end{array}$ \\
\hline $\begin{array}{c}\text { Coifl } \\
\text { et } \\
\text { wavel } \\
\text { et }\end{array}$ & $\begin{array}{c}8.14 \\
7\end{array}$ & $\begin{array}{c}0 . \\
20 \\
7\end{array}$ & $\begin{array}{l}0.36 \\
832\end{array}$ & $\begin{array}{l}0.0 \\
01 \\
68\end{array}$ & $\begin{array}{l}0.35 \\
809\end{array}$ & $\begin{array}{l}0.3 \\
28 \\
09\end{array}$ & $\begin{array}{c}53.1 \\
117\end{array}$ & $\begin{array}{r}30 . \\
11 \\
17\end{array}$ & $\begin{array}{c}128 \\
0.62 \\
89\end{array}$ & $\begin{array}{l}488 \\
.62 \\
89\end{array}$ \\
\hline
\end{tabular}

The results reveal that biorthogonal wavelet and daubechies wavelet exhibits similar performance on understanding the characteristics of soil nutrients from the images. First principle component of coiflet wavelet exhibits strong correlation with $\mathrm{pH}$ level, whereas the fourth and fifth components are underperforming. Cumulatively, biorthogonal 
and daubechies wavelets provide substantial correlation with the $\mathrm{pH}$ contents than other wavelets.

They also exhibit high correlation with carbon and phosphorous contents with the principle components. They share the positions with symlet wavelet on providing good correlation with potassium level. Symlet wavelet exhibits relatively average correlation with all the nutrients with less deviation. From the analysis, we can define that the daubechies and biorthogonal wavelets are suitable to maintain a substantial relationship with the soil nutrients.

\section{PREDICTION ANALYSIS}

\subsection{Methodology}

To ensure the correlation performance of the selected wavelets and their principle components, we attempt to use feedforward neural network to investigate the prediction performance. A dedicated neural network for every soil nutrient is constructed with 20 neurons in its single hidden layer.

The training library consists of $\left\{A^{1 D}\right\}$ as input attributes and the nutrient level as the target variables. Levenberg-Marquardt (LM) algorithm is used to train the neural network and the Mean squared error (MSE) is set as the objective function to be minimized. Random division process is exploited to segregate the training library and hence training and validation of the neural network is performed. Test images are acquired for the same region, but from point of capturing, and applied to the neural network for predicting the soil nutrients.

\subsection{Results}

The actual nutrient level and the predicted level by the neural network are tabulated in Table II. The results have produced that the performance of all the wavelets are not consistent with respect to the nutrients. Daubechies wavelet performs better in predicting carbon and phosphorous content of the soil. However, it performs poorer than other wavelets, when predicting potassium and electrical conductivity of the soil. Biorthogonal wavelet dominates on predicting the $\mathrm{pH}$ level, whereas symlet and coiflet wavelets dominate on predicting potassium and electrical conductivity of the soil, respectively.

\subsection{Discussion}

When comparing the outcome of prediction analysis with that of the correlation analysis, we can identify the coinciding effect between both the outcomes. For instance, the first principle component of the daubechies and biorthogonal wavelets has correlated well with the $\mathrm{pH}$ level of the soil samples, as per Table I. Table II states biorthogonal wavelet has produced least prediction error for $\mathrm{pH}$ level. The similarities persist when studying the carbon, phosphorous and potassium contents also, except electrical conductivity. This reveals that the wavelet features that exhibit strong correlation with the soil nutrients level can help in predicting them using remote sensing imagery.

\subsection{Implications}

Since the results are encouraging, the challenges ahead in the chemical analysis on estimating the soil nutrients can be overcome by using remote sensing imagery. The remote sensing imagery can assist well in understanding the nature of the soil, its nutrient enrichment, their quantity, etc. This application can further assist not only in agriculture, but also for infrastructural development, urban development and other commercial proposals.

\section{CONCLUSION AND FUTURE WORK}

This paper reported the outcomes of both the correlation analysis and the prediction analysis on remote sensing imagery. The correlation analysis has revealed the dominating wavelets and their principle components that correlate well with the chemical report. The outcomes have been highly supported by the prediction analysis performed using neural network. By comparing the results of the correlation analysis and the prediction analysis, the wavelets that are able to correlate well with the chemical report have produced substantial prediction accuracy on the remote sensing imagery. These results are highly encouraging to use remote sensing imagery for predicting the soil nutrients and their quantity. In the future work, we have planned to consider extensive features of the remote sensing images to ensure precise prediction of soil nutrients.

\section{ACKNOWLEDGEMENTS}

Our thanks to the experts who have contributed us during soil sample collection and its testing.

\section{REFERENCES}

[1] Xuelei Wang., C.M. Mannaerts., Shengtian Yang., Yunfei Gao and Donghai Zheng., "Evaluation of soil nitrogen emissions from riparian zones coupling simple processoriented models with remote sensing data", Science of the Total Environment 408, pp. 3310-3318, 2010.

[2] Kneubuhler, M., Damm, A., Schweiger, A.K., Risch, A.C., Schutz, M. and Schaepman, M.E., "Continuous Fields From Imaging Spectrometer Data for Ecosystem Parameter Mapping and Their Potential for Animal Habitat Assessment in Alpine Regions", IEEE Journal of Selected Topics in Applied Earth Observations and Remote Sensing, vol. 7, no. 6, 29 May 2014.

[3] Vandana Tomar., Vinay Prasad Mandal., Pragati Srivastava., Shashikanta Patairiya., Kartar Singh., Natesan Ravisankar., Natraj Subash. and Pavan Kumar., "Rice Equivalent Crop Yield Assessment Using MODIS Sensors' Based MOD13A1-NDVI Data", IEEE Sensors Journal, vol. 14, no. 10, pp. 3599-3609, October 2014.

[4] Lin Qiu., Xiaomin Chen. and Jianjun Pan., "In situ measurement of soil macropores by dye tracing and image analysis", 2013 Second International Conference on Agro-Geoinformatics (Agro-Geoinformatics), IEEE, pp. $13-17,12-16$ Aug. 2013.

[5] Zheng Hongbo., Wu Jianping. and Zhang Shan., "Study on the Spatial Variability of Farmland Soil Nutrient Based on the Kriging Interpolation", International Conference on Artificial Intelligence and Computational Intelligence, 2009. AICI'09, vol. 4, pp. 550 - 555, 7-8 Nov. 2009.

[6] Lei Chen ; Saileung Ng, "Economic loss of soil erosion in Linyi City", 2011 IEEE International Conference on Remote Sensing, Environment and Transportation Engineering (RSETE), pp. 259-262, 2011.

[7] Ustin, L., Asner, G.P., Gamon, J.A., Huemmrich, K.F., Jacquemoud, S., Schaepman, M. and Zarco-Tejada, P., "Retrieval of Quantitative and Qualitative Information about Plant Pigment Systems from High Resolution Spectroscopy", IEEE International Conference on Geoscience and Remote Sensing Symposium, 2006. IGARSS 2006, pp. 1996 - 1999, July 31 2006-Aug. 4 2006. 
[8] A. Gitelson., M. N. Merzlyak. and O. B. Chivkunova., "Optical properties and nondestructive estimation of anthocyanin content in plant leaves," Photochem. Photobiol., vol. 74, no. 1, pp. 38-45, Jul. 2001.

[9] Vina, A. and Gitelson, A.A., "Sensitivity to Foliar Anthocyanin Content of Vegetation Indices Using Green Reflectance", IEEE on Geoscience and Remote Sensing Letters, vol. 8, no. 3, pp. 464 - 468, May 2011.

[10] Bach, H. and Mauser, W., "Methods and examples for remote sensing data assimilation in land surface process modeling", IEEE Transactions on Geoscience and Remote Sensing, vol. 41, no. 7, Part: 1, pp. 1629-1637, 2003.

[11] Lihua Xu. and Deti Xie., "Prediction for Available Nitrogen and Available Phosphorus by Using Hyperspectral Data", 2nd International Conference on Remote Sensing, Environment and Transportation Engineering (RSETE), 1-3 June 2012.

[12] Peng Lu., Zheng Niu. and Linghao Li., Prediction of Soil Organic Carbon by Hyperspectral Remote Sensing Imagery", Third Global Congress on Intelligent Systems (GCIS), 2012, pp. 291- 293, 2012.

[13] Lianqinq Xue, Dan Li, Shuo Huang and Chunlin Wu., "Spatial Variability Analysis on Soil Nitrogen and Phosphorus Experiment Based on Geostatisics", International Workshop on Education Technology and Training and International Workshop on Geoscience and Remote Sensing, ETT and GRS 2008., Vol. 2, pp. 237 240, 2008.

[14] Nafiseh Ghasemi, Mahmod Reza Sahebi, and Ali Mohammadzadeh, "Biomass Estimation of a Temperate Deciduous Forest Using Wavelet Analysis", IEEE Transactions on Geoscience and Remote Sensing, Vol. 51, No. 2, 2013

[15] David J. Mulla., "Twenty five years of remote sensing in precision agriculture: Key advances and remaining knowledge gaps", Biosystems Engineering; Special Issue: Sensing in Agriculture 114, 358 - 371, 2013.

[16] Amor V.M. Ines., Narendra N. Das., James W. Hansen.and Eni G. Njoku., "Assimilation of remotely sensed soil moisture and vegetation with a crop simulation model for maize yield prediction", Remote Sensing of Environment, vol. 138, pp. 149-164, November 2013

[17] Elizabeth M. Isenstein. and Mi-Hyun Park., "Assessment of nutrient distributions in Lake Champlain using satellite remote sensing", Journal of Environmental Sciences, vol. 26, no. 9, pp. 1831-1836, 1 September 2014.

[18] Qinhong Liao., Jihua Wang., Cunjun Li. and Xiaohe Gu., "Estimation of fluvo-aquic soil organic matter from hyperspectral reflectance by using discrete wavelet transformation", IEEE 2012 First International Conference on Agro-Geoinformatics (AgroGeoinformatics), pp. 1-5, 2012

[19] Heng Dong., Chao Chen., Jinliang Wang., Qiming Qin., Hongbo Jiang., Ning Zhang., Mingchao Liu, "Study on quantitative retrieval of soil nutrients", 2011 IEEE International Geoscience and Remote Sensing Symposium (IGARSS), pp. 3330- 3333, 2011.

[20] Hongyan Chen., Gengxing Zhao., Yinjuan Wang., Long Sui. and $\mathrm{Hu}$ Meng., "Discussion on remote sensing estimation of soil nutrient contents", 2011 International Conference on Remote Sensing, Environment and Transportation Engineering (RSETE), pp. 3072-3075, 2011.

[21] Cheng - Wen, Chang, David Laird, Maurice J. Mausbach and Charles R.Hurburg Jr., "Near-Infrared Reflectance Spectroscopy - Principal Components Regression Analyses of Soil Properties", Soil Society of American Journal, vol. 65, no. 2, pp. 480-490, 2001.

[22] Qiang Ma., Wantai Yu. and Hua Zhou., "The relationship between soil nutrient properties and remote sensing indices in the Phaeozem region of Northeast China", 2010 IEEE Second International Conference on Computational Intelligence and Natural Computing Proceedings (CINC), vol. 2, pp.109- 112, 2010.

[23] V.A.Gulhane and S.V.Rode, "Correlation Analysis on Soil Nutrients and Wavelet Decompositions of Satellite Imagery", Accepted to publish in proceedings of International Conference on Industrial Instrumentation and Control (ICIC 2015), Pune, India 